\section{KẾT LUẬN}

Triêu chứng lâm sàng và điên chẩn cơ trong tổn thương dây thân kinh quay rất đa dạng: 10,9\% không mất vận động, 14,1\% không mất cảm giác... phụ thuộc vào vị trí, thời gian và hình thái tổn thương. Dây thân kinh quay có tiên lượng phục hồi tốt $71,9 \%$, có liên quan tới thời gian phát hiện và điều trị, hình thái tổn thương và dấu hiệu trên điện chẩn cơ.

\section{TÀI LIẸU THAM KHẢO}

1. BumbasirevicM, PalibrkT, LesicA, và cộng sự (2016). Radial nerve palsy. EFORT Open $\operatorname{Rev}, \mathbf{1}(\mathbf{8}), 286-294$.

2. SeddonH. J.(1942). A Classification of Nerve Injuries. Br Med J,2(4260),237-9.

3. ShaoY. C, HarwoodP, GrotzM. R và cộng sự (2005). Radial nerve palsy associated with fractures of the shaft of the humerus: a systematic review. J Bone Joint Surg Br,87(12),1647-52.
4. HeB, ZhuZ, ZhuQ và cộng sự (2014). Factors predicting sensory and motor recovery after the repair of upper limb peripheral nerve injuries. Neural Regen Res, $9(6), 661-72$.

5. Võ Đôn, Nguyển Hữu Công (2018). Đặc điểm điên sinh lỳ trong chấn thương thần kinh ngoại biển. Y học TP. Hồ Chí Minh,1(Phụ bản tập 22),211-216.

6. SzyłejkoA., Bielecki, M , Terlikowski, R. (2015). Epidemiology of upper limb peripheral nerve injuries in the material collected in the Department of Orthopedics and Traumatology Medical University of Bialystok. Progress in Health Sciences,5(1),130-137.

7. LaulanJ. (2019). High radial nerve palsy. Hand Surg Rehabil,38(1),2-13.

8. SchwabT. R,StillhardP. F, Schiblis và công sư (2018). Radial nerve palsy in humeral shaft fractures with internal fixation: analysis of management and outcome. Eur J Trauma Emerg Surg, 44(2), 235-243.

\title{
NGHIÊN CỨU CHỈ SỐ SỨC CĂNG DỌC THẤT TRÁI BẰNG SIÊU ÂM ĐÁNH DẤU MÔ Cơ TIM Ở BỆNH NHÂN MẮC BỆNH MẠCH VÀNH MẠN TÍNH
}

\section{TÓM TẮT}

Mục tiêu: Đánh giá chỉ số sức căng dọc thất trái (Left ventricular global longitudinal strain - LVGLS) và mối liên quan với một số chỉ số siêu âm tim 2D ở người mắc bệnh mạch vành mạn tính. Đối tượng và phương pháp: 43 bệnh nhân bệnh mạch vành mạn tínhđã được chẩn đoán xác định bằng chụp mạch vành qua đường ống thông, sau đó được thực hiện siêu âm tim, phân tích kết quả đánh dấu mô bằng phần mềm QLAB version 9.0. Kết quả: Giá trị LVGLS trung bình của nhóm nghiên cứu là $-15,69 \pm 4,07 \%$. Với mức hẹp mạch vành đáng kể ( $\geq 70 \%)$ được xác định bằng chụp mạch vành, giá trị cut-off của LVGLS $=-17,95 \%$, độ nhạy 85\%, độ đặc hiệu 54,55\% (p < $0,05)$; LVGLS có mối liên quan với giảm vận động vùng $(p<0,05)$ và có mối tương quan nghịchvới $E F$ Simpson Biplane trên siêu âm tim 2D $(r=-0.46, p<$ $0,05)$. Kết luận: Sức căng dọc thất trái trên siêu âm đánh dấu mô cơ tim giảm ở người mắc BMVMT, giá trị cut-off để tiên lượng hẹp mạch vành đáng kể là $17,95 \%$, có mối liển quan với giảm vận động vùng và tương quan nghịch với phân suất tống máu EF Simpson Biplane trên siêu âm tim 2D.

Tư khóa: Bệnh mạch vành mạn tính, Siêu âm đánh dấu mô cơ tim, chỉ số sức căng dọc thất trái.

*Viên Y học Phòng không - Không quân **Bệnh viện Quân y 103

Chịu trách nhiệm chính: Đặng Đình Đôn Email: donlampart1301@gmail.com Ngày nhận bài: 3/5/2021

Ngày phản biện khoa học: 4/6/2021

Ngày duyệt bài: 16/6/2021

\section{SUMMARY}

ELEVATING LEFT VENTRICULAR GLOBAL LONGITUDINAL STRAIN(LVGLS) INDEX ON ECHOCARDIOGRAPHY 2D IN PATIENTS

\section{WITH CHRONIC CORONARY DISEASE}

Purposes: To elevate left ventricular global longitudinal strain (LVGLS) index and the relationship with several indexes on echocardiography 2D in patients with chronic coronary disease. Subjects and methods: Including 43 patients with chronic coronary disease diagnosed by angiography, then performed echocardiography, analysis results ofspeckle trackingechocardigraphy by QLAB version 9.0 software. Results: Mean of LVGLS is $-15,69 \pm 4,07 \%$. With level of significant coronary stenosis ( $\geq 70 \%)$ is confirmed by angrography, cut-off value of LVGLS is $17,95 \%$, the sensitivity is $85,71 \%$, the specificity is $54.55 \%(p<0,05)$. LVGLS has the relationship with regional hypokinesis $(p<0,05)$ and the inverse correlation with EF simpson biplane on echocardiography $2 D(r=-$ $0.46 p<0,05)$. Conclusions: Left ventricular global longitudinal strain on speckle tracking echocardigraphy reduce in patients with chronic coronary disease. Its cut-off value to prognosis significant coronary stenosis is $-17,95 \%$, it has the relationship with regional hypokinesis and the inverse correlation with ejection fraction simson biplane on echocardiography 2D.

Key word: Chronic coronary disease; speckle tracking echocardigraphy; left ventricular global longitudinal strain. 


\section{I. ĐĂT VẤN ĐỀ}

Bênh mach vành mạn tính (hay bênh tim thiếu máu cục bộ mạn tính - BTTMCBMT) là bệnh thường gặp, nhất là ở các nước phát triển và có xu hướng gia tăng nhanh ở các nước đang phát triển, trong đó có Việt Nam. Hiện nay BTTMCBMT đã đứng hàng thứ 5 trong số các bệnh lý tim mạch [2].

Siêu âm tim thông thường giúp hỗ trợ các bác sĩ lâm sàng trong việc chẩn đoán và tiên lượng BMVMT. Tuy nhiên, việc ước lượng trực quan các bất thường chuyển động thành đôi khi không chính xác trong việc phát hiện thiếu máu cục bộ cơ tim. Siêu âm đánh dấu mô cơ tim (Speckle tracking echocardigraphy - STE) là một kỹ thuật mới. Trong đó, thông số biến dạng cơ tim giúp đánh giá sự suy giảm chức năng tim kín đáo từ rất sớm, khi mới có bất thường về chức năng của mô, chưa có biến đổi về hình thái của tim.

Siêu âm đánh dấu mô cơ tim (STE) là một công cụ không xâm lấn có thể dễ dàng thực hiện và nhanh chóng cung cấp thông tin bổ sung qua siêu âm tim cơ bản, vì nó có thể phát hiện tổn thương cơ tim tinh vi và xác định được vùng thiếu máu cục bộ phù hợp với tổn thương mạch vành, có được hình ảnh rõ ràng với một bản đồ hữu ích cho việc chẩn đoán[8]. Các vùng cơ tim bị thiếu máu có thể được đánh giá qua sự thay đổi của nhiều thông số biến dạng và tốc độ biến dạng. Trong đó, sức căng dọc toàn bộ (GLS) là thông số STE được sử dụng nhiều nhất để đánh giá tình trạng xơ hóa cơ tim sớm của tất cả các buồng tim; biểu thi mắt bò của toàn bô thất trái (LVGLS) cung cấp đánh giá khu vực tổn thương thất trái theo vùng mạch vành chi phối và phân tích cụ thể các đăc tính biến dạng thành nội tâm mạc với phân tích 3 lớp [4]. Vì vây, chúng tôi thực hiện đề tài này với mục tiêu "Đánh giá sức căng dọc tâm thu thất trái bằng siêu âm đánh dấu mồ cơ tim và mối liên quan với môt số chi số trên siêu âm tim $2 D$ ở người mắc bệnh tim thiếu máu cục bộ mạn tính"

\section{II. ĐỐI TƯƠNG VÀ PHƯƠNG PHÁP NGHIÊN CỨU}

2.1. Đối tượng nghiên cứu. Gồm 43 bệnh nhân mắc BTTMCBMT đã được chẩn đoán xác định bằng chụp mạch vành qua đường ống thông với mức độ hẹp $\geq 50 \%$ đường kính lòng. tại Trung Tâm Tim mạch - Bệnh viện Quân y 103 từ 9/2020 đến tháng 5/2021.

\subsection{Phương pháp nghiên cứu}

- Thiết kế nghiên cứu : mô tả cắt ngang, lấy mẫu thuân tiên.

- Cách thức tiến hành nghiên cứu: Tất cả các bệnh nhân được thực hiện

+ Chụp mạch vành chẩn đoán BTTMCBMT.

+ Siêu âm tim 2D, đánh giá rối loạn vận động vùng, phân suất tống máu EF Simpson Biplane (EFSSBP), Thể tích cuôi tâm trương theo Teicholz (EDV - End diastolic volume), Thể tích cuối tâm thu theo Teicholz(ESV - End systolic volume).

+ Siêu âm đánh dấu mô cơ tim, đánh giá chỉ số GLS.

- Số liệu được lưu trữ trên Excel, xử lýbằng phần mềm SPSS 22.0.

- Tính giá trị trung bình, tỷ lệ, so sánh hai giá trị trung bình bằng $\mathrm{t}$-test, so sánh hai tỷ lệ bằng kiểm định $X^{2}$.

\section{KẾT QUẢ NGHIÊN CỨU}

Độ tuổi trung bình của 43 bệnh nhân trong nhóm nghiên cứu của chúng tôi là $71,54 \pm 6,65$, tuổi thấp nhất là 52 , cao nhất là 83 ; số bệnh nhân trên 70 tuổi chiếm tỷ lệ chủ yếu $(62,79 \%)$.

Tỷ lệ Nam/Nữ là 3.3/1

Bảng 1. Tý lệ mức độ tổn thương $Đ M V$

\begin{tabular}{|c|c|c|}
\hline $\begin{array}{c}\text { Mức độ tốn } \\
\text { thương ĐMV }\end{array}$ & $\begin{array}{c}\text { Số lướng } \\
\text { (n) }\end{array}$ & $\begin{array}{c}\text { Tỷ lệ } \\
\text { (\%) }\end{array}$ \\
\hline $\begin{array}{c}\text { Hẹp nhẹ: } 50- \\
70 \%\end{array}$ & 17 & 39,53 \\
\hline $\begin{array}{c}\text { Hẹp vừa: 71- } \\
\text { 90\% }\end{array}$ & 17 & 39,53 \\
\hline $\begin{array}{c}\text { Hẹp nặng: > } \\
\text { 90\% }\end{array}$ & 9 & 20,93 \\
\hline Tống & $\mathbf{4 3}$ & $\mathbf{1 0 0 , 0 0}$ \\
\hline
\end{tabular}

Nhận xét: Tỷ lệ bệnh nhân có mức độ tốn thương mạch vành nhe (50-70\%) và vừa chiếm tỷ lệ cao hơn (39.53\%) so với nhóm bệnh nhân bị hẹp mạch vành mức độ nặng $(20.93 \%)$. Tỷ lệ bệnh nhân có mạch vành hẹp đáng kể (> 70\%) là $60.46 \%$.

Bảng 2. Một số đặc điểm trên siêu âm tim 2D

\begin{tabular}{|c|c|c|c|c|}
\hline \multicolumn{2}{|c|}{ Chỉ số } & $\bar{x}_{ \pm}$SD & $\begin{array}{c}\text { Số lượng } \\
\text { (n) }\end{array}$ & $\begin{array}{l}\text { Tý lệ } \\
(\%)\end{array}$ \\
\hline \multicolumn{2}{|c|}{ EDV $(\mathrm{ml}))$} & $\begin{array}{c}106,76 \pm \\
37,03\end{array}$ & 43 & 100 \\
\hline \multicolumn{2}{|c|}{$\mathrm{ESV}(\mathrm{ml})$} & $\begin{array}{c}38,12 \pm \\
30,24\end{array}$ & 43 & 100 \\
\hline \multirow{3}{*}{\begin{tabular}{|c} 
EF \\
Simpson \\
Biplane(\%) \\
Giảm vận \\
động vưng \\
\end{tabular}} & $\begin{array}{c}<40 \% \\
40-49 \% \\
\geq 50 \%\end{array}$ & $\begin{array}{c}62,84 \pm \\
11,52\end{array}$ & \begin{tabular}{|c|}
3 \\
12 \\
28
\end{tabular} & \begin{tabular}{|c|}
6,98 \\
27,91 \\
65,11
\end{tabular} \\
\hline & \multirow{2}{*}{\multicolumn{2}{|c|}{$\begin{array}{l}\text { Có } \\
\text { Khôn }\end{array}$}} & 12 & 27,90 \\
\hline & & & 31 & 72,10 \\
\hline
\end{tabular}

Nhận xét: Đa số bệnh nhân có phân suất tống máu EF bảo tồn $(65,11 \%)$. Bệnh nhân có phân suất tống máu giảm nặng chiểm tỷ lệ thấp $(6,98 \%)$; Số bệnh nhân có giảm vận động vùng chiếm tỷ lệ thẩp hơn $(27,90 \%)$ so với số không giảm vận động vùng $(72,10 \%)$. 
Bảng 3. Đặc điểm chỉ số LVGLS trên siêu âm đánh dấu mô cơ tim

\begin{tabular}{|c|c|c|c|}
\hline LVGLS Giới & Nam & Nũ & $\begin{array}{c}\text { X } \\
\text { SD }\end{array}$ \\
\hline LVGLS ( $\bar{x}_{ \pm}$ & $-15,54 \pm$ & $-16,22 \pm$ & $-15,69$ \\
SD) (\%) & 4,03 & 4,35 & $\pm 4,07$ \\
\cline { 2 - 3 } & \multicolumn{2}{|c|}{$\mathrm{P}=0,59$} &, \pm 07 \\
\hline
\end{tabular}

Nhân xét: Giá trị trung bình của sức căng dọc thất trái LVGLS của nhóm đối tượng nghiên cứu là $-15,69 \pm 4,07 \%$, không có sự khác biệt về LVGLS giữa hai nhóm nam và nữ $(p>0,05)$.

Bảng 4. Độ nhạy, độ đặc hiệu của giá trị GLS với hẹp động mạch vành đáng kể ( $\geq 70 \%)$ theo giá trị cut-off

\begin{tabular}{|c|c|c|c|c|}
\hline \multirow{2}{*}{$\begin{array}{c}\text { Mức độ hẹp } \\
\text { GLS\% }\end{array}$} & \multicolumn{2}{|c|}{$<\mathbf{7 0} \%$} & \multicolumn{2}{c|}{$\geq \mathbf{7 0 \%}$} \\
\cline { 2 - 5 } & $\mathbf{N}$ & $\mathbf{\%}$ & $\mathbf{N}$ & $\mathbf{\%}$ \\
\hline$<-17.95 \%$ & 12 & 54.55 & 3 & 14.29 \\
\hline$\geq-17.95 \%$ & 10 & 45.45 & 18 & 85.71 \\
\hline Tống & $\mathbf{2 2}$ & $\mathbf{1 0 0 \%}$ & $\mathbf{2 1}$ & $\mathbf{1 0 0 \%}$ \\
\hline
\end{tabular}

Nhận xét: Với giá trị cut-off bằng $-17.95 \%$, LVGLS có độ nhay $85.71 \%$, độ đặc hiệu $54.55 \%$ với hẹp động mạch vành đáng kể ( $\geq 70 \%)$.

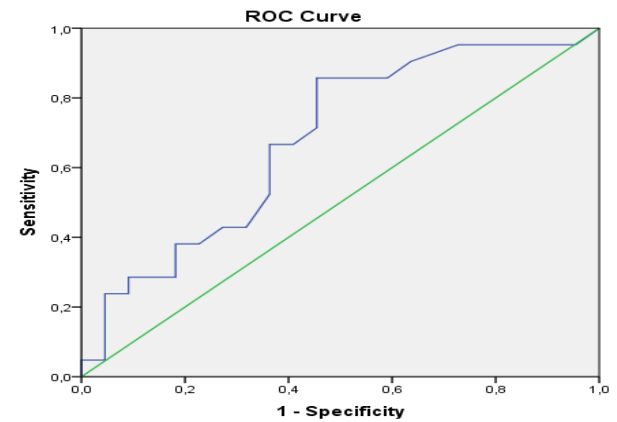

Hình 1. Đường cong ROC biểu thị giá trị chẩn đoán hẹp mạch vành đáng kể ( $\geq 70 \%$ ) của GLS (Diện tích dưới đường cong $\mathrm{S}_{\mathrm{GLS}} \%=0,68$ với $p<0,05$, điểm cut-off: -17,95\%)

Báng 5. Mối liên quan giữa sức căng dọc thất trái với $R L V \bigoplus$ vùng

\begin{tabular}{|c|c|c|c|c|c|}
\hline \multirow{2}{*}{ Whóm } & \multicolumn{2}{|c|}{$\begin{array}{c}\text { Giảm vận } \\
\text { động vừng } \\
(\mathrm{n}=12)\end{array}$} & \multicolumn{2}{|c|}{$\begin{array}{l}\text { Không giảm } \\
\text { vận động vùng } \\
(n=31)\end{array}$} & \multirow[t]{2}{*}{ p } \\
\hline & $\mathrm{N}$ & $\%$ & $\mathrm{~N}$ & $\%$ & \\
\hline & 1 & 8,33 & 14 & 45,1 & \\
\hline$>-17,9$ & 11 & 91,67 & 17 & 54,84 & $0,0<$ \\
\hline$\overline{\bar{x}_{ \pm}}$ & -13 & $\pm 3,78$ & -17 & $\pm 2,46$ & 0,00 \\
\hline
\end{tabular}

Nhân xét: Với giá trị cut-off của LVGLS bằng $-17,95 \%$, nhóm giảm vận động vùng có tỷ lệ giảm LVGLS nhiều hơn so với nhóm không giảm vận động vùng $(p<0,05)$. Mặt khác, giá trị trung bình của LVGLS ở nhóm giảm vận động vùng cũng thấp hơn so với nhóm không giảm vận động vùng $(p<0,05)$.

Bảng 6. Tương quan giữa chi số LVGLS với phân suất tông máu đo bằng phương pháp Simpson Biplane

\begin{tabular}{|c|c|c|}
\hline Chỉ số & r & P \\
\hline EFSSBP & -0.46 & 0.02 \\
\hline EDV-2D & 0.46 & 0.002 \\
\hline ESV-2D & 0.56 & 0.001 \\
\hline
\end{tabular}

Nhận xét: Chỉ số LVGLS có mối tương quan nghịch mức độ vừa với chỉ số EFSSBP $(r=-0.46$, $\mathrm{p}<0,05)$, tưởing quan thuận mức độ vừa với chì số $E D V-2 D(r=0,46 ; p=0.002)$ và chỉ số ESV$2 D(r=0,56 ; p<0,05)$

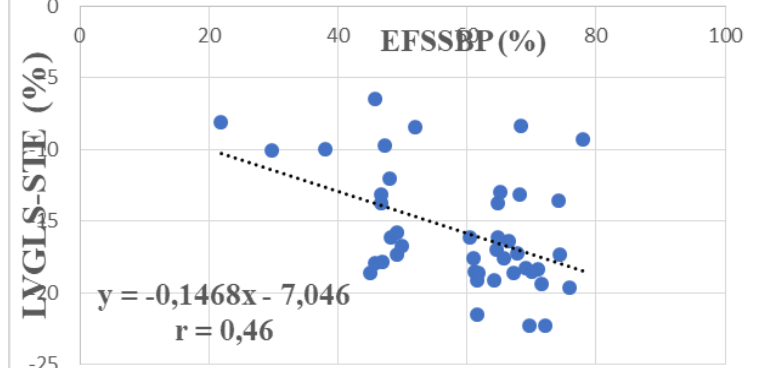

Biểu đồ 1. Tương quan giữa chỉ số LVGLS-STE và chi số EFSSBP

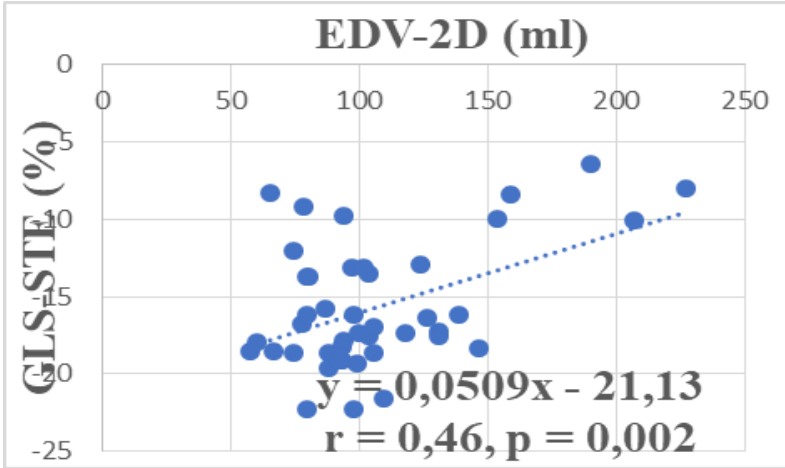

Biểu đồ 2 và 3. Tương quan giữa chỉ số LVGLS-STE và chỉ số EDV, ESV 


\section{BÀN LUÂN}

Trong nghiên cứu của chúng tôi, bệnh nhân hẹp mạch vành đáng kể (> 70\%) chiếm tỷ lệ chủ yếu $(60,46 \%)$, đây là những bệnh nhân có chỉ đinh điêu tri đắt Stent ĐMV.

Sức căng dọc thất trái giữa 2 nhóm đối tượng lần lượt là $-15,53 \pm 4,03 \%$ và $-16,22 \pm 4,35 \%$ và sức căng dọc thất trái trung bình của 43 bệnh nhân trong nhóm nghiên cứu là $-15,69 \pm 4,07$. Giá tri trung bình này thấp hơn so với nghiên cứu trên 43 người bình thường của Nguyễn Thị Diễm là $-16,52 \pm 1,19[1]$, phù hợp kết quả nghiên cứu của Hanan Radwan và cs (2017) với ngưỡng giá trị tối ưu của GLS để dự đoán BMVMT là $-15,6 \%$. Chúng tôi tiến hành vẽ đường cong ROC của chỉ số LVGLS theo phân loaị tổn thương động mạch vành đáng kể ( $\geq$ $70 \%$ ), chúng tôi thấy rằng chỉ số LVGLS có khả năng chẩn đoán tổn thương hẹp động mạch vành đáng kể với giá trị cut-off là $-19.75 \%$, diện tích dưới đường cong là 0.68 . Dựa vào giá trị cut-off, chúng tôi thâyy rằng chỉ số LVGLS trong chẩn đoán hẹp động mạch vành $\geq 70 \%$ đường kính lòng mạchcó độ nhạy $85,71 \%$, độ đặc hiệu $54.55 \%$. Từ đó thây rằng, chỉ số LVGLS là một chỉ số khá tốt trong chẩn đoán hẹp động mạch vành đáng kể. Kết quả này phù hợp với một số nghiên cứu khác trên thế giới như nghiên cứu của Choi J. O và cộng sự (2009) cũng chỉ ra giá trị cut-off của GLS bằng $-17,9 \%$ có độ nhạy $79 \%$ và độ đặc hiệu 79\% [5].

Đánh giá giảm vận động vùng trên siêu âm tim 2D là phương pháp quan sát trực quan khả năng vận động của các thành, vách của tim. Phương pháp này mang tính chủ quan, phụ thuộc vào kinh nghiệm người làm siêu âm. Siêu âm STE lượng giá được sự biến đổi chỉ số GLS bán tự động, cho ra giá trị có độ tin cậy trong đánh giá mức độ biến dạng cơ tim. Trong nghiên cứu của chúng tôi, với ngưỡng cut-off của GLS bằng $-17,95 \%$, nhận thây có mối liên quan giữa giảm sức căng dọc thất trái với giảm vận động vùng trên siêu âm tim $2 D(P<0,05)$. Chỉ số LVGLS càng tăng (giá trị âm), giảm vận động vùng càng nặng.

Đánh giá GLS bằng kỹ thuật bán tự động STE là khả thi, nhanh chóng và cung cấp thông tin định lượng, cho thấy sự đồng thuận tốt hơn với tiêu chuẩn tham chiếu khi so với EF được thực hiên bởi người đọc có kinh nghiêm khác nhau. Điều này có thể là do việc lựa chọn vị trí ranh giới của người đọc có xu hướng ít thay đổi hơn khi họ tinh chỉnh bán tự động so với khi vẽ đường viên theo cách thủ công [7]. Kalam K. (2014) và cs đã thực hiện đánh giá có hệ thống các bằng chứng từ các nghiên cứu quan sát so sánh GLS với $\mathrm{EF}$ trong việc dư đoán các biến cô tim bất lợi chính đi đến kết luận rằng: có bằng chứng chắc chắn về giá trị tiên lượng của GLS và vượt trội so với EF để dự đoán các biến cố tim bất lợi chính [6]. Trong nghiên cứu của chúng tôi, giá trị trung bình của LVGLS (giá trị âm) có mối tương quan nghịch mức độ vừa với phân suất tống máu $(p<0,05)$, điều này có nghĩa là khi sức căng dọc thất trái càng tăng (giá trị âm) thì phân suất tống máu thất trái càng giảm.

Trong thực hành lâm sàng, GLS nên được xem xét đánh giá thường quy trong siêu âm tìm thay thế EF để tiên lượng các biến cố tim mạch trong tương lai.

\section{KẾT LUÂ̂N}

Sức căng dọc thất trái trên siêu âm đánh dấu mô cơ tim giảm ở người mắc BTTMCBMT, giá trị cut-off để tiên lượng hẹp mạch vành đáng kể là $17,95 \%$; có mối liên quan với giảm vận động vùng và tương quan nghịch mức độ vừa với phân suất tống máu EF Simpson Biplane trên siêu âm tim 2D.

\section{TÀI LIỆ THAM KHẢO}

1. Nguyễn Thi Diễm (2017), "Nghiên cứu chức năng thất trái bằng siêu âm đánh dấu mô cơ tim ở bênh nhân tăng huyết áp nguyên phát", luận án tiến sĩ, Trường đại học $Y$ dược Huế.

2. Bô̂ $Y$ tế, Thực hành chẩn đoán và điều trị bệnh động mạch vành. 2020. p. Tr 54-55.

3. Phạm Văn Cuộc (2011), "Nghiên cứu đặc điểm hội chứng chuyển hóa ở bênh nhân Bệnh tim thiếu máu cục bộ man tính", Luận văn chuyên khoa cấp 2, Học viện Quần y.

4. Cameli M., et al. (2019), "More than 10 years of speckle tracking echocardiography: Still a novel technique or a definite tool for clinical practice?", Echocardiography, 36(5), 958-970.

5. Choi J. O., et al. (2009), "Longitudinal 2D strain at rest predicts the presence of left main and three vessel coronary artery disease in patients without regional wall motion abnormality", Eur J Echocardiogr, 10(5), 695-701.

6. Kalam K., Otahal P., Marwick T. H. (2014), "Prognostic implications of global LV dysfunction: a systematic review and meta-analysis of global longitudinal strain and ejection fraction", Heart, 100(21), 1673-80.

7. Medvedofsky D., et al. (2017), "Reproducibility and experience dependence of echocardiographic indices of left ventricular function: Side-by-side comparison of global longitudinal strain and ejection fraction", Echocardiography, 34(3), 365-370.

8. Pastore M. C., et al. (2021), "Speckle Tracking Echocardiography: Early Predictor of Diagnosis and Prognosis in Coronary Artery Disease", Biomed Res Int, 2021, 6685378. 